\title{
Magnetic resonance imaging in degenerative ataxic disorders
}

\author{
I E C Ormerod, A E Harding, D H Miller, G Johnson, D MacManus, \\ E P G H du Boulay, B E Kendall, I F Moseley, W I McDonald
}

Institute of Neurology, London, UK

NMR Research Group

I E C Ormerod

D H Miller

G Johnson

D MacManus

W I McDonald

University

Department of

Clinical Neurology

I E C Ormerod

A E Harding

D H Miller

G Johnson

D MacManus

W I McDonald

Department of

Neuroradiology,

National Hospital for

Neurology and

Neurosurgery,

London, UK

E P G H du Boulay

B E Kendall

I F Moseley

Correspondence to

Professor A E Harding,

Urofessor A E Harding,

University Department of

of Neurology, Queen

of Neurology, Queen

3BG, UK.

Received 4 December 1992

and in revised form

16 March 1993.

Accepted 15 April 1993

\begin{abstract}
MRI of the brain was performed in 53 patients with a variety of degenerative ataxias and related disorders and 96 control subjects. Atrophy of intracranial structures was not seen in patients with the pure type of hereditary spastic paraplegia, or in early cases of Friedreich's ataxia. In advanced Friedreich's ataxia there was atrophy of the vermis and medulla. The MRI features of early onset cerebellar ataxia with retained reflexes were variable, and suggest heterogeneity. In autosomal dominant cerebellar ataxias, most patients had cerebellar and brainstem atrophy, probably reflecting the pathological process of olivopontocerebellar atrophy; there was no clearly defined group with both clinical and imaging features of isolated cerebellar involvement. The MRI abnormalities in idiopathic late onset cerebellar ataxia were predominantly those of cerebellar and brainstem atrophy or pure cerebellar atrophy. The clinical and imaging features of brainstem abnormalities were discordant in several patients. Pure cerebellar atrophy was associated with slower progression of disability. Cerebral atrophy was common in the late onset ataxias. Cerebral white matter lesions, although usually few in number, were observed in significantly more patients than controls, particularly those aged over 50 years.
\end{abstract}

(于 Neurol Neurosurg Psychiatry 1994;57:51-57)

The degenerative ataxias are a heterogeneous group of disorders, many of which are genetically determined. Their clinical features are diverse, with variable degrees of cerebral hemisphere, brainstem, spinal cord, and peripheral nerve dysfunction in addition to cerebellar ataxia. Classification of these dis-

Table 1 Control subjects and patients studied

\begin{tabular}{llll}
\hline Disease category & Number & $\begin{array}{l}\text { Age range } \\
\text { (years) (mean) }\end{array}$ & $\begin{array}{l}\text { Disease duration range } \\
\text { (years) (mean) }\end{array}$ \\
\hline Controls & 96 & $18-73(41)$ & N/A \\
Friedreich's ataxia & 6 & $13-38(23)$ & $9-25(15)$ \\
Early onset ataxia/retained reflexes & 6 & $17-42(28)$ & $1-27(14)$ \\
Autosomal dominant cerebellar ataxia & 14 & $22-66(49)$ & $2-25(16)$ \\
Idiopathic late onset cerebellar ataxia & & & \\
$\quad$ with other features & 10 & $39-73(61)$ & $3-14(7)$ \\
$\quad$ pure & 10 & $38-64(51)$ & $2-30(10)$ \\
Hereditary spastic paraplegia & 7 & $13-39(27)$ & $2-33(14)$ \\
\hline
\end{tabular}

orders is difficult; early attempts were based exclusively on pathological findings, but it has been suggested that disease categories can be more usefully defined using clinical and genetic criteria. ${ }^{1}$ Autopsy data are relatively scarce and a reliable method for definition of involved structures during life could contribute to classification and more precise diagnosis. Computerised tomography has a limited role to play in this respect, as images of posterior fossa structures are usually of relatively poor quality compared with those of the cerebral hemispheres. Magnetic resonance imaging provides superior images of the brainstem and cerebellum, ${ }^{2-6}$ and has been used to study small series of patients with degenerative ataxic disorders with useful definition of the distribution of atrophy in the brain. ${ }^{7-9}$ In larger series it has been suggested that MRI offers a useful adjunct to clinical features for diagnostic and prognostic purposes. ${ }^{1011}$ We report on 53 patients with a variety of degenerative ataxias studied by MRI, comparing the findings in different disease groups, and also with those seen in 96 control subjects.

\section{Subjects}

CONTROLS

MRI was performed in 96 control subjects aged 18-73 years (table 1). Sixty-four were aged less than 50 years and 32 were 50 years or over. Seventy-six of these were normal volunteers from the Salvation Army or from the staff of the National Hospital who were not examined clinically but who had no previous neurological history. The remainder (20) were neurological control subjects who were investigated at the National Hospital for disorders of peripheral nerves or the spinal cord that are not associated with brain pathology. These patients had no signs attributable to neurological dysfunction above the foramen magnum.

\section{PATIENTS}

Of the 53 patients with ataxia (table 1), 30 were aged under 50 years and 23 were aged 50 years or more. They were subdivided into six categories on clinical grounds (table 1). There were six patients with Friedreich's ataxia $^{12}$ and six with early onset cerebellar ataxia with retained reflexes. ${ }^{13}$ Fourteen patients had autosomal dominant cerebellar ataxia (ADCA; table 2); seven had additional features such as supranuclear ophthalmoplegia, pseudobulbar palsy, and mild dementia 
Table 2 Clinical and imaging features of patients with autosomal dominant cerebellar ataxia

\begin{tabular}{|c|c|c|c|c|c|c|c|c|c|c|c|}
\hline \multirow[b]{2}{*}{ No. } & \multirow{2}{*}{$\begin{array}{l}\text { Age } \\
\text { (years) }\end{array}$} & \multirow{2}{*}{$\begin{array}{l}\text { Duration } \\
\text { (years) }\end{array}$} & \multirow{2}{*}{ Type } & \multirow[b]{2}{*}{ Features } & \multicolumn{6}{|l|}{ Atrophy } & \multirow[b]{2}{*}{$W M L$} \\
\hline & & & & & $\mathrm{CH}$ & Vermis & Medulla & Pons & Midbrain & Cerebrum & \\
\hline $\begin{array}{l}1 \\
2 \\
3 \\
4^{\star} \\
5^{\star} \\
6 \\
7 \\
8 \\
9 \\
10 \\
11 \\
12 \\
13 \\
14\end{array}$ & $\begin{array}{l}55 \\
48 \\
61 \\
61 \\
60 \\
34 \\
51 \\
29 \\
56 \\
66 \\
61 \\
34 \\
53 \\
20\end{array}$ & 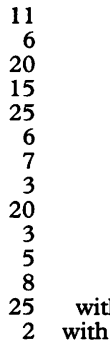 & $\begin{array}{l}\text { I } \\
\text { I } \\
\text { I } \\
\text { I } \\
\text { I } \\
\text { I } \\
\text { I } \\
\text { II } \\
\text { II } \\
\text { III } \\
\text { III } \\
\text { th ET } \\
\text { deafnes }\end{array}$ & $\begin{array}{l}\text { B,N } \\
\text { SNO } \\
\text { SNO,D } \\
\text { SNO } \\
\text { SNO } \\
\text { SNO,D,B } \\
\text { D } \\
\text { R } \\
\text { R } \\
- \\
- \\
\text { D,My,N } \\
- \\
\text { ss }\end{array}$ & $\begin{array}{l}- \\
+++ \\
- \\
+++ \\
+++ \\
+++ \\
++ \\
- \\
+++ \\
++ \\
++ \\
- \\
-\end{array}$ & $\begin{array}{l}++ \\
+++ \\
++ \\
+++ \\
+++ \\
++ \\
+++ \\
+++ \\
+++ \\
+++ \\
+++ \\
+ \\
++ \\
++\end{array}$ & $\begin{array}{l}+++ \\
- \\
- \\
++ \\
++ \\
++ \\
++ \\
++ \\
+++ \\
- \\
- \\
- \\
- \\
-\end{array}$ & $\begin{array}{l}- \\
- \\
- \\
+++ \\
++ \\
++ \\
+++ \\
++ \\
+++ \\
++ \\
++ \\
- \\
++\end{array}$ & $\begin{array}{l}- \\
- \\
- \\
++ \\
- \\
- \\
++ \\
++ \\
++ \\
- \\
- \\
-\end{array}$ & $\begin{array}{l}++ \\
- \\
- \\
++ \\
++ \\
+ \\
++ \\
++ \\
++ \\
++ \\
+ \\
++ \\
++ \\
-\end{array}$ & $\begin{array}{l}+ \\
- \\
+ \\
+ \\
+ \\
- \\
- \\
- \\
- \\
+ \\
+ \\
+ \\
-\end{array}$ \\
\hline
\end{tabular}

(ADCA type I), two had maculopathy (ADCA type II), three a later onset pure cerebellar syndrome (ADCA type III), ${ }^{14}$ and three more unusual dominant ataxias, including a syndrome of ataxia, dementia, and myoclonus exhibiting paternal transmission. Ten patients had idiopathic late onset cerebellar ataxia (table 3$)^{15}$ with other clinical features such as supranuclear ophthalmoplegia, peripheral neuropathy, mild dementia, optic atrophy, and parkinsonism (ILOCA/O). All presented with ataxia and this remained the predominant feature. Only one had clinical or investigative evidence of autonomic failure and thus fulfilled the criteria for a diagnosis of multiple system atrophy ${ }^{16}$. Ten had pure ILOCA (ILOCA/P) - that is, no neurological dysfunction other than a cerebellar syndrome ${ }^{15}$. The last group consisted of seven patients with hereditary spastic paraplegia, either with the pure form (five cases) or with additional clinical features. ${ }^{17}$

Each patient was examined by one of the authors (IECO or AEH). The case notes of all patients were individually reviewed by AEH for the purpose of diagnostic classification, which was made according to previously published criteria. ${ }^{1}$ For patients with ILOCA, disability was assessed on a four point scale: (1) mild ataxia, able to work; (2) unable to work, able to walk and perform activities of daily living; (3) as (2), but unable to walk unassisted or chairbound; (4) chairbound, dependent on others for activities of daily living. A severity score related to disease duration was obtained by dividing disability score by disease duration in years and multiplying by 100 .

\section{Methods}

MAGNETIC RESONANCE IMAGING

All subjects were examined on a Picker $0.5 \mathrm{~T}$ MR imaging system. Multi-slice, contiguous $5 \mathrm{~mm}$ thick axial T2-weighted spin echo (SE $2000 / 60$ ) images were taken throughout the brain, to optimise the detection of white matter lesions. Axial inversion recovery (IR $2000 / 40 / 500$ ) images were performed in most subjects to facilitate assessment of cerebral atrophy. T1-weighted (IR 2000/500/40 or SE 500/40) sagittal images were obtained in most control subjects and all patients, to assess the degree of atrophy of the posterior fossa structures.

Table 3 Clinical and imaging features of idiopathic late onset cerebellar ataxia

\begin{tabular}{|c|c|c|c|c|c|c|c|c|c|c|c|}
\hline \multirow[b]{2}{*}{ No. } & \multirow{2}{*}{$\begin{array}{l}\text { Age } \\
\text { (years) }\end{array}$} & \multirow{2}{*}{$\begin{array}{l}\text { Duration } \\
\text { (years) }\end{array}$} & \multirow{2}{*}{$\begin{array}{l}\text { Disability } \\
\text { score }\end{array}$} & \multirow[b]{2}{*}{ Features } & \multicolumn{6}{|l|}{ Atrophy } & \multirow[b]{2}{*}{$W M L$} \\
\hline & & & & & $\mathrm{CH}$ & Vermis & Medulla & Pons & Midbrain & Cerebrum & \\
\hline \multicolumn{12}{|c|}{ ILOCA (O) } \\
\hline 15 & 62 & 6 & 33 & $\mathrm{P}, \mathrm{A}$ & - & ++ & - & ++ & - & - & + \\
\hline 16 & 66 & 14 & 21 & D & +++ & +++ & ++ & - & + & +++ & + \\
\hline 17 & 57 & 4 & 50 & $\mathrm{D}, \mathrm{SNO}$ & +++ & +++ & - & - & - & ++ & + \\
\hline 18 & 68 & 4 & 50 & D & ++ & +++ & + & - & - & + & + \\
\hline 19 & 73 & 8 & 25 & $\mathrm{OA}$ & - & - & - & - & ++ & ++ & + \\
\hline 20 & 64 & 3 & 67 & $\mathbf{P}$ & ++ & ++ & - & +++ & - & - & - \\
\hline 21 & 64 & 6 & 33 & SNO & ++ & ++ & - & - & - & ++ & + \\
\hline 22 & 62 & 7 & 28 & $\mathbf{N}$ & ++ & +++ & + & $++t$ & + & ++ & + \\
\hline 23 & 39 & 9 & 22 & $\mathbf{N}$ & +++ & +++ & - & ++ & ++ & - & - \\
\hline 24 & 54 & 9 & 22 & $\mathbf{N}$ & ++ & ++ & - & - & - & ++ & + \\
\hline \multicolumn{12}{|c|}{$\operatorname{ILOCA}(\mathrm{P})$} \\
\hline 25 & 41 & 3 & 33 & - & +++ & +++ & + & + & - & - & - \\
\hline 26 & 38 & 2 & 100 & - & +++ & +++ & - & ++ & - & +++ & + \\
\hline 27 & 64 & 4 & 11 & - & ++ & ++ & - & - & - & ++ & + \\
\hline 28 & 62 & 30 & 67 & - & +++ & +++ & - & - & - & ++ & + \\
\hline 29 & 56 & 2 & 150 & - & ++ & +++ & ++ & +++ & ++ & ++ & - \\
\hline 30 & 39 & 8 & 12 & - & +++ & +++ & ++ & ++ & ++ & - & - \\
\hline 31 & 41 & 5 & 22 & - & +++ & +++ & - & - & - & ++ & - \\
\hline 32 & 60 & 11 & 27 & - & + & +++ & - & - & - & - & - \\
\hline 33 & 56 & 6 & 50 & - & ++ & +++ & - & ++ & - & - & - \\
\hline 34 & 56 & 27 & 11 & - & ++ & +++ & - & - & - & ++ & - \\
\hline
\end{tabular}

Abbreviations as in table 2 , plus $\mathrm{P}=$ parkinsonism; $\mathrm{A}=$ autonomic failure; $\mathrm{OA}=$ optic atrophy. ILOCA(O) $=$ idiopathic late onset cerebellar ataxia with other neurological dysfunctions; ILOCA $(\mathbf{P})=$ ataxia alone. 
Table 4 Frequency of cerebral white matter lesions

\begin{tabular}{|c|c|c|c|}
\hline Age (years) & No. & . & No. with lesions (\%) \\
\hline $\begin{array}{l}\text { Control subje } \\
18-49 \\
50-59 \\
60-69 \\
70-79\end{array}$ & $\begin{array}{r}63 \\
19 \\
10 \\
2\end{array}$ & & $\begin{array}{l}3(5) \\
4(21) \\
4(40) \\
2(100)\end{array}$ \\
\hline \multicolumn{2}{|c|}{ Category (no.) } & No. with lesions & No. aged $<50$ with lesions \\
\hline \multicolumn{2}{|c|}{$\begin{array}{l}\text { Friedreich's ataxia (6) } \\
\text { Early onset cerebellar ataxia with retained }\end{array}$} & 0 & 0 \\
\hline \multicolumn{2}{|c|}{ Autosomal dominant cerebellar ataxia (14) } & $\begin{array}{l}1 \\
7\end{array}$ & $\begin{array}{l}1 \\
1 / 5\end{array}$ \\
\hline \multicolumn{2}{|c|}{$\begin{array}{l}\text { Idiopathic late onset cerebellar ataxia with } \\
\text { other neurological dysfunction }(10)\end{array}$} & 7 & $\mathbf{0}$ \\
\hline \multicolumn{2}{|c|}{$\begin{array}{l}\text { alone (10) } \\
\text { Hereditary spastic paraplegia (7) }\end{array}$} & $\begin{array}{l}2 \\
3\end{array}$ & $\begin{array}{l}0 \\
3\end{array}$ \\
\hline
\end{tabular}

ASSESSMENT OF MRI

The MR images of both controls and patients were intermingled and examined for the presence of atrophy. Atrophy was qualitatively graded on a four point scale ( $0=$ no atrophy, $1=$ mild, $2=$ moderate and $3=$ severe) by IFM) who reported by consensus without prior knowledge of the diagnosis. Atrophy of cerebellar hemispheres, cerebellar vermis, medulla, pons, midbrain, and cerebral hemispheres was rated in this way for each patient. Cerebral white matter lesions were defined as areas of hyperintensity on T2-weighted images of at least three pixels, excluding small caps at the frontal or occipital poles.

\section{Results}

MRI IN NORMAL CONTROL SUBJECTS

Mild atrophy of the brainstem was found in 50 years. In two subjects more than one part of the brainstem was considered atrophic. Mild atrophy of the cerebellar hemispheres was seen in four subjects and three were aged under 50 years. The vermis was atrophic in 10 subjects, all of whom were over 50 years; in nine of these there was also atrophy of the cerebral hemispheres. The cerebral hemispheres were atrophic in $\mathbf{4 2}$ control subjects; the degree of atrophy was mild in 35 and moderate in seven cases. Nineteen of 35 with

Figure 1 T1 weighted (SE 500/40) sagittal MRI of two patients with Friedreich's ataxia. (A) a 14 year old boy with symptoms of seven years' duration. MRI is normal; (B) a 38 year old woman who had had symptoms for 25 years. MRI shows atrophy of the cerebellum brainstem, and upper cervical cord. two experienced neuroradiologists (BEK and six subjects and of these three were aged over

mild atrophy were over the age of 50 years, and 10 of these also had white matter lesions in the cerebral hemispheres. Five of seven with moderate atrophy were over the age of 50 years and four of these had cerebral white matter lesions.

Lesions within the cerebral white matter were seen in three subjects $(5 \%)$ aged less than 50 years and in $10(30 \%)$ subjects aged 50 years or over (table 4 ). This difference was highly significant $\left(\chi^{2}, \mathrm{p}<0.001\right)$. In the three subjects in the younger group there were only minor lesions within the cerebral white matter in two and smooth periventricular signal change in one. Of the 10 older subjects with cerebral lesions, four were aged 50-59 years; three of these showed minor changes but one had extensive periventricular and white matter lesions. Six of the subjects aged 60 years or over had white matter abnormalities. These were minor in four (with some smooth periventricular change and a few small scattered lesions in the cerebral white matter) and two had more extensive abnormalities.

\section{MRI IN PATIENTS}

Only two of the patients with hereditary spastic paraplegia, both with additional cerebellar signs and aged less than 50 years, had mild or moderate atrophy of intracranial structures, the brainstem, cerebellum, and cerebrum in one, and the vermis and cerebrum in the other. Both of these patients had white matter lesions, as did another with the pure disease. MRI was normal in the four other patients with pure disease.

MRI was normal in two patients with Friedreich's ataxia (fig 1a). Four of the six patients, all with disease duration greater than 15 years, had moderate medullary atrophy which was associated with lesser changes in the pons and midbrain. Only one of these patients had marked cerebellar hemisphere atrophy (fig 1b) and two had moderate or severe atrophy of the vermis. None of the patients with Friedreich's ataxia had cerebral atrophy or white matter lesions.

The MRI features of early onset cerebellar ataxia were variable. MRI was normal in one patient with recent onset (within two years). Only one had severe cerebellar hemisphere

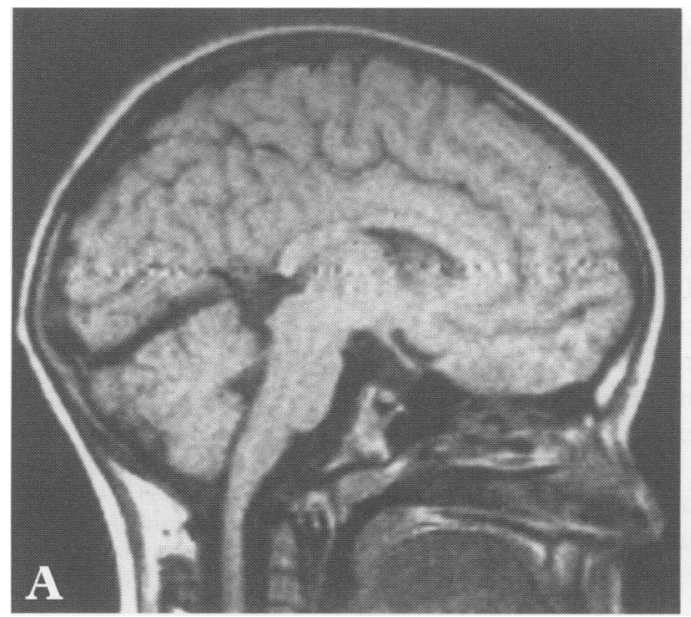


Figure 2 T1-weighted (SE 500/40) sagittal MRI of a 41 year old woman with pure idiopathic late onset cerebellar ataxia (case 25) showing marked atrophy of the cerebellar hemispheres (A) and vermis (B). The brainstem is normal.
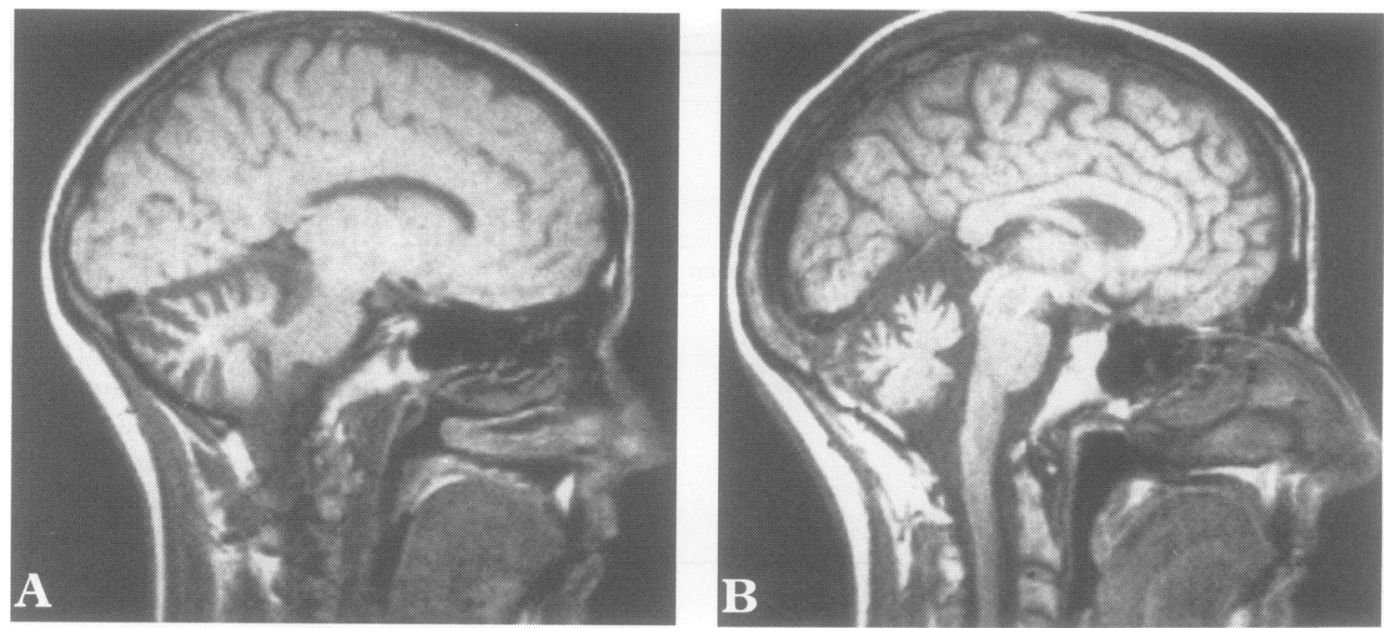

atrophy, associated with mild atrophy of the vermis, pons and cerebral hemispheres. Two patients had mild or moderate vermis atrophy, one with mild cerebral atrophy. One had atrophy of the whole of the brainstem, and the sixth had vermis, brainstem, and cerebral atrophy with scanty periventricular white matter lesions.

Of the 14 patients with ADCA, eight had moderate or severe cerebellar hemisphere atrophy, and all but one atrophy of the vermis (table 2). Five of seven of those with ADCA type I had brainstem atrophy, predominantly involving the pons, although in one it was confined to the medulla; six of these patients had clinical evidence of brainstem dysfunction. Brainstem involvement was seen in both patients with ADCA type II, and both with type III, a pure cerebellar syndrome, although disease duration was relatively short in the latter.

Marked cerebellar hemisphere and vermis atrophy was frequent in patients with ILOCA/O, a disorder clinically similar to ADCA type $I$, but almost universal in the pure type of ILOCA (fig 2). Seven of the 10 patients with ILOCA/O had brainstem atrophy, again maximally involving the pons; in two this was confined to the midbrain or medulla. Two of the patients with supranuclear ophthalmoplegia had normal brainstem images. Two patients with ILOCA/O had extrapyramidal features and both of these had moderate or severe pontine atrophy. Brainstem atrophy without clinical correlate was seen in five of the 10 patients with ILOCA/P, including all those with disease durations of less than five years (fig 3 ). Disability score was significantly higher in the 11 patients with brainstem atrophy on MRI (excluding case 18 who only had mild medullary atrophy, $p<0.01$, Wilcoxon's rank sum test). A major contribution to this result came from four patients, two with a pure cerebellar syndrome, clinically and radiologically, who had a very benign course (cases 28 and 34 ), and two with a rapidly progressive pure cerebellar syndrome of short duration who had striking brainstem atrophy on MRI (cases 26 (fig 3) and 29).
Cerebral hemisphere atrophy was present in 50 per cent or more of patients in these three groups of late onset ataxic disorders, being least common in ILOCA/P. Dementia was observed in three patients with ADCA; one had gross cerebral atrophy without white matter lesions, one had periventricular and white matter lesions but no significant cerebral atrophy, and in the third the cerebral hemispheres appeared normal. Three patients with ILOCA/O were demented. All had cerebral atrophy and two had white matter lesions.

There was no significant effect (KruskallWallis analysis of variance) of disease duration in any of the seven diagnostic groups which might explain the distribution or severity of atrophy in these patients. Moderate or severe cerebral, vermis, and cerebellar atrophy was more frequent $(\mathrm{p}<0.003, \mathrm{p}<0.001$ and $\mathrm{p}<0.002$, respectively) in patients aged over 50 years than in patients under 50 years, but all the patients with early onset ataxia and Friedreich's ataxia were in the younger group. A significant difference was found between the frequency of lesions within the cerebral hemispheres (fig 4), either periventricular or discrete within the cerebral white matter, in

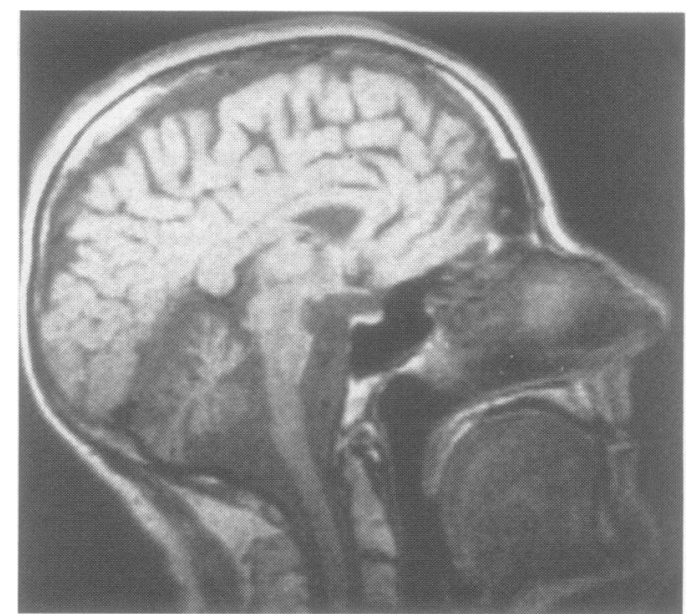

Figure 3 T1-weighted (SE 500/40) sagittal MRI of a 59 year old woman with pure idiopathic late onset cerebellar ataxia of two years' duration (case 29). There is marked atrophy of the cerebellum and brainstem. 
the seven groups $(p<0.05$, analysis of variance; table 4). As stated, these were uncommon in patients with Friedreich's ataxia, early onset ataxia, and spastic paraplegia. In the diagnostic categories which included more older patients (ADCA, ILOCA/O and ILOCA/P), the lesions occurred mainly in patients over the age of 50 years. The effect of age on the frequency of the lesions was therefore analysed and comparison was made between the patients and the normal control subjects. Significantly more patients over the age of 50 years had lesions than younger patients $\left(\chi^{2}, \mathrm{p}<0.005\right)$. More patients had lesions than controls, and this difference was more marked for patients over the age of $\mathbf{5 0}$ years $\left(\chi^{2} \mathrm{p}<0.03\right)$ than for those aged less than 50 years $\left(\chi^{2}, p<0.05\right)$. When the frequency of lesions was analysed with respect to disease duration, no significant association was found (Kruskall-Wallis one way analysis of variance). Only marked atrophy of the cerebral hemispheres was associated with the presence of lesions $\left(\chi^{2}, p<0.02\right)$. When the groups were subdivided further to compare the effect of age $(<50$ years and $\geqslant 50$ years) and atrophy of the brain on the presence of lesions, no significant differences were found.

The cerebrospinal fluid had been examined in 26 patients but none, of the control subjects. One patient had oligoclonal immunoglobulin. This was a 60-year-old woman with an 11 year history of a progressive ataxic syndrome which was clinically classified as a pure type of ILOCA. The MRI demonstrated some atrophy of the cerebellar hemispheres and a more marked atrophy of the cerebellar vermis but there were no lesions in the cerebral hemispheres. Two patients, with ADCA and a pure type of spastic paraplegia respectively, showed elevated cerebrospinal immunoglobulin:albumin ratios at $12 \%$ and $18 \%$.

\section{Discussion}

In this series of patients with degenerative ataxias, the presence of atrophy of brainstem and cerebellar structures on MRI scans was generally in accord with previous pathological observations. The normal findings in pure hereditary spastic paraplegia reflect the fact that degenerative changes in this disease are usually confined to the spinal cord. ${ }^{18}$ In Friedreich's ataxia, necropsy studies have shown marked atrophy of the spinal cord but the brainstem, cerebellum and cerebrum are usually normal, apart from some atropy of the medulla and degenerative changes in the cerebellar peduncles. ${ }^{19}$ CT studies have reported mild atrophy of the cerebrum and more marked vermis atrophy in some, usually advanced, cases. ${ }^{20}$ Some of our patients, who had had the disease for a long time, had atrophy of the vermis, medulla, pons, or midbrain with changes in the medulla being most frequent and striking. Klockgether and colleagues $^{11}$ reported essentially similar MRI findings to those described here in
Friedreich's ataxia; they also described prominent atrophy of the cervical cord which we did not assess in detail.

These authors compared the imaging findings in Friedreich's ataxia with those in early onset cerebellar ataxia with retained reflexes, and found a high incidence of cerebellar hemisphere and vermis atrophy in the latter, with less prominent brainstem atrophy. The MRI features in our cases of this syndrome were rather variable. Neuropathological studies in such patients are extremely scarce, showing olivopontocerebellar atrophy (OPCA) in two cases. ${ }^{21} 22$ The MRI features reported here and by others ${ }^{11}$ do not suggest OPCA in most cases, and indicate that this syndrome is pathologically and genetically heterogeneous.

Pathological heterogeneity is well recognized in ADCA. Most, but not all, patients with the clinical features of ADCA types I and II have OPCA at necropsy. There is some variation in pathological findings within large families. ${ }^{1}$ Six of our nine patients in these two categories had MRI findings suggesting OPCA. The same applied to two of three with ADCA type III, a later onset pure cerebellar syndrome in which one pathological report has shown cerebello-olivary atrophy. ${ }^{23}$ Thus brainstem involvement is by no means always manifest clinically, regardless of disease duration. Most patients with clear clinical evidence of brainstem dysfunction showed brainstem atrophy on MRI. Five of six patients with ADCA type I and supranuclear ophthalmoplegia had significant atrophy of the pons or midbrain, or both. In these patients with ADCA, there was no clearly defined group with both clinical and imaging features of isolated cerebellar involvement.

ILOCA has been divided on pathological grounds into OPCA and cerebello-olivary atrophy, the latter with sparing of the brainstem apart from the inferior olives. Atrophy of the cerebellar hemispheres is seen in both groups, which may represent ILOCA/O and ILOCA/P respectively. These disorders are difficult to differentiate clinically early in the course of the disease as both usually present with an isolated cerebellar syndrome. For these reasons it has been suggested that the two disease groups cannot be distinguished for at least the first four years after onset of symptoms. ${ }^{10}$ In our patients severe atrophy of the cerebellum (hemispheres and vermis) was seen in nearly all patients. Seven patients (four with ILOCA/P) had moderate or marked atrophy of the pons, vermis, and cerebellar hemispheres compatible with a morphological diagnosis of OPCA. In two others with ILOCA/P, there was cerebellar atrophy combined with atrophy of the medulla or midbrain, sparing the pons. Several patients with non-cerebellar features had normal brainstem images. In both ADCA and ILOCA, it is well recognized that pathological findings do not always have clinical correlates and vice versa, ${ }^{1}$ and the same appears to apply to imaging abnormalities.

Chida and colleagues ${ }^{24}$ assessed pontine 
volume on CT scans and correlated this with the clinical picture in a mixed group of adult onset ataxias. They found that pontine atrophy was significantly correlated with the presence of autonomic and extrapyramidal features, but this differentiation was not absolute. Klockgether and coworkers ${ }^{10}$ used MRI to study 28 patients with ILOCA, of whom 13 had additional non-cerebellar features. They were able to identify a group of patients with clinical and imaging features of a pure cerebellar syndrome and proposed that this diagnosis should be reserved for patients with a disease duration greater than four years, in whom there is a pure cerebellar syndrome and where imaging shows atrophy only affecting the cerebellum. Of the patients with additional features, 11 had brainstem atrophy. The authors acknowledged that some patients with pure cerebellar atrophy had non-cerebellar features but that the clinical and imaging abnormalities were not those of OPCA, as is true of five patients in this series; they suggested that these patients had some other undefined multisystem degeneration. Of our patients with ILOCA/P, four had a disease duration of four years or less at the time of assessment and three of these had atrophy of brainstem structures as well as cerebellum. The remaining six patients with ILOCA/P had been symptomatic for up to 30 years; two had atrophy of the brainstem and four had atrophy of only the cerebellum. Thus in our patients the combined clinical and imaging parameters did not allow an absolute distinction between OPCA and disease restricted largely to the cerebellum, regardless of disease duration.

The importance of detecting clinical or radiological evidence of brainstem dysfunction was stressed by Klockgether and colleagues, ${ }^{10}$ who suggested that this indicated a relatively poor prognosis. It is notable that all their 13 patients with combined cerebellar and brainstem disease had additional parkinsonism, several had bulbar dysfunction, and five were incontinent of urine. It seems highly likely that a significant proportion of these patients had multiple system atrophy, even though none had overt orthostatic hypotension. Only one of our patients (case 15) had this condition, diagnosable on the basis of the presence of autonomic failure, and autonomic function tests were normal in the rest. The other patients in this series with ILOCA and the MRI appearances of brainstem atrophy did exhibit a more rapid disease course than those with pure cerebellar atrophy, although this was not as striking as in the study of Klockgether and colleagues. ${ }^{10}$ This difference can be explained by the lower proportion of cases in our series with probable multiple system atrophy. This disease has a poor prognosis compared with ILOCA. ${ }^{15} 16$

Asymptomatic periventricular and white matter lesions were visible on MRI in a number of our normal control subjects, with increasing frequency in the older age groups. Such changes have been correlated with pathological changes secondary to small ves- sel disease. ${ }^{25-27}$ Their increasing frequency with age could be a manifestation of minor vascular insults accrued by the brain over the passage of time. Other studies have found such abnormalities in a similar proportion of older subjects. ${ }^{28-30}$

Our patients had significantly more lesions than the age matched control subjects and this difference was more apparent in those aged over 50 years. The reason for this excess of cerebral white matter lesions in patients with degenerative ataxic disorders is unclear. There was no evidence that any of these patients had multiple sclerosis; the only one with oligoclonal immunoglobulin in her cerebrospinal fluid did not have white matter lesions. The presence of white matter lesions was correlated with the radiological appearance of severe cerebral atrophy. Neuronal fall out and gliosis in the place of the axons may be the explanation for these, as the fibre tracts connecting the cortical neurons, particularly from the frontal lobes, course the periventricular areas. Alternatively, perhaps compliance changes in the presence of atrophy, and perivascular foci of degeneration are more likely to occur, this being the major pathological substrate of MRI white matter lesions in asymptomatic individuals. ${ }^{31}$ Such mechanisms remain speculative in the absence of definitive pathology, but it is of interest that a similar excess of white matter lesions is seen in another degenerative (and atrophic) disorder, Alzheimer's disease. $^{32}$

Other MRI studies ${ }^{61011}$ in patients with cerebellar ataxias have not commented upon white matter changes in the cerebral hemispheres. Savoiardo and colleagues ${ }^{8}$ studied 23 patients with OPCA and noted signal change within the cerebellum and brainstem and some changes in the putamen in patients with a clinical picture of multiple system atrophy. These abnormalities were not observed in our study, but in the previous one some of the patients were examined on a high field system $(1.5 \mathrm{~T})$ and coronal images of the brainstem and cerebellum were made routinely, which the authors found helpful in demonstrating these changes. ${ }^{8}$

The frequency of the white matter lesions in the present series of patients is very much less than that seen in patients with multiple sclerosis. In patients with clinically definite disease, ${ }^{33}$ periventricular lesions were demonstrated in $112 / 114$ patients on the same imaging system. ${ }^{9}$ The number of white matter lesions in our ataxic patients was also usually small. An isolated progressive cerebellar syndrome is uncommon in multiple sclerosis, but the diagnosis is often considered in this context, particularly early in the course of the disease and in younger patients. MRI is of diagnostic assistance in such cases, as the presence of extensive periventricular and discrete white matter lesions is much more in favour of multiple sclerosis, particularly in patients under the age of 50 years. Also, the degree of cerebellar and brainstem atrophy seen in many patients described here is 
uncommon other than in advanced cases of multiple sclerosis.

In conclusion, MRI is of great value in distinguishing degenerative disorders from those due to structural or inflammatory lesions in the patient presenting with a cerebellar syndrome who has no affected relatives or specific diagnostic features. It is clearly the preferred imaging examination in this context. MRI also has a role to play in the precise diagnosis of these disorders. The present study indicates that moderate to severe brainstem with or without cerebellar atrophy at the time of presentation should point against a diagnosis of Friedreich's ataxia or hereditary spastic paraplegia. The presence of brainstem atrophy in a patient with a late onset pure cerebellar syndrome predicts more rapid progression than if the brainstem is spared, ${ }^{10}$ and should also suggest investigation for other features of multiple system atrophy. MRI has not yet, however, solved all the long established difficulties in classifying the degenerative ataxias. MRI technology has made major advances while this series of patients was being studied. With high field systems, it is now possible to obtain much better resolution, and there are methods for allowing accurate quantitation of area/volume of regions of interest. ${ }^{34}$ Newer strategies such as diffusion imaging, magnetisation transfer imaging, and spectroscopy offer the possibility of greater pathological specificity. A further study of degenerative ataxias using such developments would be worthwhile.

We wish to thank the Multiple Sclerosis Society of Great Britain and Northern Ireland, the Medical Research Council, and the Brain Research Trust for financial support, and all the clinicians who allowed us to study their patients.

1 Harding AE. The hereditary ataxias and related disorders. Edinburgh: Churchill Livingstone, 1984

2 Han JS, Bonstelle CT, Kaufman B, et al. Magnetic resonance imaging in the evaluation of the brainstem. Radiology 1984;105:705-12.

3 Bodley TM, Cohen DA, Schatz NJ, et al. Comparison of metrizamide computed tomography and magnetic resonance imaging in the evaluation of lesions at the cervicomedullary junction. Neurology 1985;35:485-92.

4 Flannagan BD, Bradley WG, Mazziota JC, et al. Magnetic resonance imaging of the brainstem: normal structure and basic functional anatomy. Radiology 1985;154: and basic

5 Ormerod IEC, Bronstein A, Rudge P, et al. Magnetic resonance in clinically isolated lesions of the brain stem. 7 Neurol Neurosurg Psychiatry 1986;49:737-43.

6 Bydder GM, Steiner RE, Thomas DJ, et al. Nuclear resonance of the posterior fossa: 50 cases. Clin Radiol 1983;34:173-88.

7 Nabatame H, Fukuyama H, Akiguchi I, et al. Spinocerebellar degeneration: qualitative and quantitative $M R$ analysis of atrophy. F Comput Assist Tomogr 1988;12: 298-303.

8 Savoiardo M, Strada L, Girotti F, et al. Olivopontocerebellar atrophy: MR diagnosis and relationship to multisystem atrophy. Radiology 1990;174:693-6.
9 Ormerod IEC, Miller DH, McDonald WI, et al. The role of NMR imaging in the assessment of multiple sclerosis and isolated neurological lesions. A quantitative study. Brain 1987;110:1579-1616.

10 Klockgether J, Schroth G, Diener H-C, Dichgans J. Idiopathic cerebellar ataxia of late onset: natural history and MRI morphology. 7 Neurol Neurosurg Psychiatry 1990;53:297-305.

11 Klockgether T, Peterson D, Grodd W, Dichgans J. Early onset cerebellar ataxia with retained tendon reflexes. Clinical, electrophysiological and MRI observations in comparison with Friedreich's ataxia. Brain 1991; comparison wit

12 Harding AE. Friedreich's ataxia: a clinical and genetic study of 90 families with an analysis of early diagnostic criteria and intrafamilial clustering of clinical features. Brain 1981;104:589-620.

13 Harding AE. Early onset cerebellar ataxia with retained tendon reflexes: a clinical and genetic study of a disorder distinct from Friedreich's ataxia. $\mathcal{f}$ Neurol Neurosurg Psychiatry 1981;44:503-8.

14 Harding AE. The clinical features and classification of the late onset autosomal dominant cerebellar ataxias: a study of eleven families, including descendants of the 'Drew family of Walworth'. Brain 1982;105:1-28.

15 Harding AE. 'Idiopathic' late onset cerebellar ataxia. A clinical and genetic study of 36 cases. $f$ Neurol Sci clinical and gen

16 Quinn N. Multiple system atrophy-the nature of the beast. I Neurol Neurosurg Psychiatry 1989;52(suppl.): 78-89.

17 Harding AE. Hereditary 'pure' spastic paraplegia: a clinical and genetic study of 22 families. $\mathcal{F}$ Neurol Neurosurg Psychiatry 1981;44:871-83.

18 Behan WMH, Maia M. Strumpell's familial spastic paraplegia: genetics and neuropathology. $\mathcal{F}$ Neurol Neurosurg Psychiatry 1974;37:8-20.

19 Oppenheimer DR. Brain lesions in Friedreich's ataxia. Can f Neurol Sci 1979;6:173-6.

20 Claus D, Aschoff JC. Cranial computerised tomography in spinocerebellar atrophies. Ann NY Acad Sci in spinocerebel

21 Fickler A. Klinische und pathologisch-anatomische Beitrage zu den Erkrankungen des Kleinhirns. Dtsche Z Beitrage zu den Erkrankungen
Nervenheilkd 1911;41:306-75

22 Jellinger $\mathrm{K}$, Tarnowska-Dziduszko E. Die ZNSVeranderungen bei den olivo-ponto-cerebellaren Atrophien. Z Neurol 1971;199:192-214.

23 Hoffmann PM, Stuart WH, Earle KM, Brody JA. Hereditary late onset cerebellar degeneration. Neurology 1971;21:771-7.

24 Chida K, Tamura M, Kamikura I, Takasu T, Goto N. A quantitative evaluation of pontine volume by computed tomography in patients with cerebellar degeneration. Neurology 1990;40:1241-5.

25 Chimowitz MI, Awad IA, Furlan AJ. Periventricular lesions on MRI. Facts and theories. Stroke 1989;24: 7-12.

26 Fazekas F, Kleinert R, Offenbacher $\mathrm{H}$, et al. The morphological correlate of incidental punctate white matter hyperintensities on MR images. Am f Neuroradiol 1991; 12:915-22.

27 Kirkpatrick JB, Hayman LA. White-matter lesions in MR imaging of clinically healthy brains of elderly subjects: possible pathological basis. Radiology 1987;162:509-11.

28 Bradley WG, Waluch V, Wycoff RR. Differential diagnosis of periventricular abnormalities in MRI of the brain Noninv Med Imag 1984;1:35-41.

29 Brant-Zawardski M, Fein G, van Dyke C, et al. MR imaging of the ageing brain: patchy white matter lesions and dementia. Am $\mathcal{F}$ Neuroradiol 1985;6:675-82.

30 Gerard G, Weisberg LA. MRI periventricular lesions in adults. Neurology 1986;36:998-1001.

31 Awad IA, Johnson PC, Spetzler RF, Hodak JA Subcortical lesions identified on magnetic resonance Subcortical lesions identified on magnetic resonance
imaging in the elderly. 2 . Post mortem pathological imaging in the elderly. 2. Post mort

32 Scheltens P, Barkhof F, Valk J, et al. White matter lesions on magnetic resonance imaging in clinically diagnosed Alzheimer's disease. Evidence for heterogeneity. Brain 1992;115:735-48.

33 Poser CM, Paty DW, Scheinberg L, et al. New diagnostic criteria for multiple sclerosis: guidelines for research protocols. Ann Neurol 1983;13:227-31.

34 Wicks DAG, Tofts PS, Miller DH, et al. Volume measurements of multiple sclerosis lesions with magnetic resonance images: a preliminary study. Neumradiology 1992;34:475-9. 